\title{
Características microbiológicas e físico-químicas do leite de cabra submetido à pasteurização lenta pós-envase e ao congelamento
}

\author{
Microbiological and physical-chemical characteristics of goat milk after low temperature \\ time pasteurization and freezing
}

\author{
Patricia Vilhena Dias de Andrade ${ }^{\mathrm{I}}$ Marcelo Resende de Souza ${ }^{{ }^{*}}$

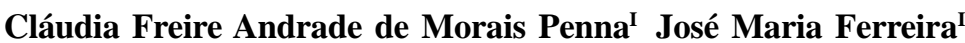

\section{RESUMO}

O objetivo principal deste trabalho foi avaliar o efeito da pasteurização lenta $\left(65^{\circ} \mathrm{C} 30 \mathrm{~min}^{-1}\right)$ em banho-maria $e$ do congelamento $\left(-18^{\circ} \mathrm{C}\right)$, seguido de estocagem por uma semana $\left(-18^{\circ} \mathrm{C}\right)$, sobre as características microbiológicas e físico-químicas do leite de cabra pré-embalado. Quinze amostras individuais de leite de cabra foram analisadas antes e após o processamento, realizado no próprio capril. A pasteurização lenta mostrou-se eficaz na redução da contaminação por mesófilos, psicrotróficos e fungos, mas a baixa contagem de coliformes fecais e totais do leite cru não proporcionou a mesma eficácia neste grupo de bactérias. O armazenamento do leite congelado durante uma semana não alterou a sua qualidade microbiológica. Não se observou influência significativa do processamento térmico sobre as concentrações dos principais constituintes do leite ou sobre as propriedades físico-químicas analisadas. Os resultados obtidos nesse experimento mostraram também que um equipamento de leitura infra-vermelha calibrado com leite bovino pode ser usado para a determinação dos teores de gordura e proteína do leite de cabra.

Palavras-chave: caprino, composição, infra-vermelho, leite, microbiologia, processamento.

\section{ABSTRACT}

The aim of this trial was to evaluate the effect of water bath low temperature long time pasteurization $\left(65^{\circ} \mathrm{C} 30\right.$ $\left.\mathrm{min}^{-1}\right)$ and freezing $\left(-18^{\circ} \mathrm{C}\right)$ followed by one-week storage $\left(-18^{\circ} \mathrm{C}\right)$ on the physical-chemical characteristics of goat milk. Fifteen individual milk samples were analyzed before and after being processed by the producer himself. Thermal processing applied was efficient for reducing mesophilic, psychrotrophic, molds and yeasts contamination, even though the low total and fecal coliform counts in raw milk did not allow the same statement considering that bacteria group. Thermal processing had no significant influence on the main constituents, concentrations or on the analyzed physical-chemical properties. The results obtained in this study also showed that infrared equipment calibrated with cow milk could be used for fat and protein determinations in goat milk.

Key words: composition, goat, infrared, microbiology, milk, processing.

\section{INTRODUÇÃO}

No Brasil, grande parte do leite de cabra é produzida em pequena escala e, muitas vezes, processada, em condições artesanais, no próprio capril. Nesses criatórios, o leite é submetido à pasteurização e pode ser em seguida congelado, a fim de facilitar a distribuição e garantir o abastecimento durante a entressafra.

O principal objetivo da pasteurização do leite é a destruição de bactérias patogênicas, mas também a eliminação de parte dos microrganismos saprófitas e a inativação de certas enzimas que prejudicam a qualidade do produto. A microbiota do leite pasteurizado depende da carga microbiana do leite cru, da eficiência da pasteurização, da extensão da recontaminação após o processamento térmico e da temperatura de estocagem (EGITO et al., 1989). Dependendo da intensidade do tratamento térmico, o aquecimento também pode provocar mudanças nas propriedades físico-químicas do leite, mas estas normalmente são insignificantes quando a temperatura não ultrapassa $60^{\circ} \mathrm{C}$ (WALSTRA \& JENNESS, 1984).

IDepartamento de Tecnologia e Inspeção de Produtos de Origem Animal, Escola de Veterinária, Universidade Federal de Minas Gerais (UFMG). Av. Antônio Carlos, 6627, 31270-901, Belo Horizonte, MG, Brasil. E-mail: mrgalo@ufmg.br.*Autor para correspondência. 
Contudo, o leite de cabra tem menor estabilidade térmica que o leite bovino (JENNESS, 1980), o que faz com que tratamentos térmicos de mesma intensidade originem alterações diferentes no leite dessas duas espécies.

O congelamento não altera as características microbiológicas do leite e o produto, logo após o descongelamento, apresenta qualidade semelhante ao leite que o originou (BENEDET \& SCHWINDEN, 1991; GOMES et al., 1997). Esse processamento também não provoca grandes modificações no sabor e no odor do leite(BENEDET \& CARVALHO, 1996), mas pode ocorrer floculação de proteínas, prejudicando a aparência do produto e sua aceitação.

A legislação brasileira (BRASIL, 2000) permite, para o leite de cabra, o uso da pasteurização rápida $\left(72-75^{\circ} \mathrm{C}\right.$ por $15-20$ segundos) ou lenta $\left(62-65^{\circ} \mathrm{C}\right.$ por 30 minutos). A pasteurização rápida é, muitas vezes, inviável para pequena escala de produção, pois a maioria dos equipamentos fabricados é destinada a um grande volume de leite, apresenta alto custo e necessita de instalações complexas. Para os pequenos laticínios e produtores, uma das soluções pode ser o uso da pasteurização lenta, que requer equipamentos de menor custo e de fácil operação e manutenção (EGITO et al., 1989), mas que exige controle mais efetivo.

Diante disso, conduziu-se este trabalho cujo principal objetivo foi avaliar a eficiência da pasteurização lenta $\left(62-65^{\circ} \mathrm{C} 30 \mathrm{~min}^{-1}\right)$ em banho-maria na redução da carga microbiana do leite de cabra préembalado, bem como verificar as possíveis alterações físico-químicas ocorridas após a pasteurização e posterior congelamento $\left(-18^{\circ} \mathrm{C}\right.$ por uma semana). $\mathrm{O}$ outro objetivo deste experimento era avaliar o uso de um aparelho de leitura infra-vermelha, calibrado com leite de vaca, na determinação dos teores de proteína e gordura do leite de cabra cru, pasteurizado fresco e congelado. Sabe-se que o leite de cabra apresenta diferenças em relação ao de vaca em certas características da gordura e da proteína, como, por exemplo, menor absorção de infra-vermelho pela proteína (-4\%) e maior pela gordura (+3,8\%) (GRAPPIN \& JEUNET, 1979; JENNESS, 1980; ZENG, 1996). Assim para que o leite de cabra seja analisado pelos mesmos métodos e aparelhos do leite de vaca, deve ser feita uma calibração apropriada (GRAPPIN \& JEUNET, 1979; GRAPPIN, 1987). No entanto, muitos laboratórios que avaliam o leite de cabra com aparelhos baseados em infra-vermelho não costumam modificar a calibração usada, pois um pequeno número de amostras de leite de cabra não justifica essa alteração.

\section{MATERIAL E MÉTODOS}

O leite foi colhido e processado em um capril localizado em Contagem - MG. O criatório era composto de animais da raça Alpina, criados em piso ripado e ordenhados manualmente duas vezes ao dia. Utilizouse o leite de quinze cabras, avaliado individualmente para obtenção de maior variabilidade. Os animais estavam em diferentes fases da lactação, mas ficavam no mesmo galpão e foram submetidos às mesmas condições de manejo. Eles eram alimentados com feno de gramíneas e concentrado comercial, fornecidos separadamente.

O leite de cada uma das cabras foi coletado em um único dia (produção total das duas ordenhas). Após a ordenha, o leite de cada animal era colocado em latas de alumínio esterilizadas. O leite da ordenha da tarde permanecia armazenado sob refrigeração $\left(0-4^{\circ} \mathrm{C}\right)$ até a manhã seguinte, quando era misturado ao leite recém-ordenhado. Desta amostra eram retiradas três alíquotas de 500mL: uma colocada em frasco de vidro estéril para ser analisada antes do processamento (amostra: leite cru, $n=15$ ) e as outras duas (leite pasteurizado fresco e pasteurizado congelado, $n=30$ ) eram manualmente embaladas em sacos de polietileno. Esses sacos eram os mesmos utilizados para embalar o leite de cabra produzido no capril e destinado à venda. Após o envase, o leite era submetido à pasteurização lenta em banho-maria $\left(65^{\circ} \mathrm{C} 30 \mathrm{~min}^{-1}\right)$, realizada no próprio capril.

O equipamento utilizado para pasteurizar o leite era muito simples: um tanque redondo de 50L em inox e com camisa dupla (aquecimento feito com vapor de água). O tanque possuía uma tampa, a qual foi acoplado um termômetro. Como o equipamento não possuía agitação mecânica, a tampa foi removida algumas vezes durante o processamento e, com uma barra de ferro, procedeu-se à agitação manual da água onde estavam os sacos de leite a fim de se obter um aquecimento homogêneo. Após a pasteurização, os saquinhos permaneciam em uma caixa d'água à temperatura ambiente $\left(16-18^{\circ} \mathrm{C}\right)$ até atingir o equilíbrio, quando eram transferidos para um tanque com água gelada $\left(0-4^{\circ} \mathrm{C}\right)$. Uma das alíquotas era separada (amostra: leite pasteurizado, $\mathrm{n}=15$ ) e a outra colocada em um freezer vertical de uso doméstico $\left(-18^{\circ} \mathrm{C}\right)$. Os saquinhos de leite eram dispostos em camada única e, após o seu completo congelamento, eram então transferidos para um freezer horizontal com a mesma temperatura que o anterior (amostra: leite congelado, $\mathrm{n}=15$ ).

Com o término do processamento, as amostras de leite cru e pasteurizado eram colocadas 
em sacola isotérmica contendo gelo e transportadas para o laboratório (Departamento de Tecnologia e Inspeção de Produtos de Origem Animal da Escola de Veterinária da Universidade Federal de Minas Gerais). As amostras de leite congelado permaneciam armazenadas no capril até o dia seguinte de sua produção, quando eram levadas ao laboratório e colocadas no congelador de uma geladeira $\left(-18^{\circ} \mathrm{C}\right)$. As análises do leite congelado eram feitas após estocagem de uma semana. Para descongelamento, manteve-se o leite na parte baixa da geladeira $\left(10-12^{\circ} \mathrm{C}\right)$, conforme instruções da embalagem. O tempo necessário para total descongelamento foi cerca de 30h.

No leite $(n=45)$ cru e após o processamento, realizaram-se as seguintes análises microbiológicas: enumeração de microrganismos mesófilos aeróbios, psicrotróficos, bolores e leveduras (APHA, 1992), coliformes totais e fecais (ICMSF, 1978). Para monitoramento da pasteurização, fez-se a pesquisa das enzimas fosfatase e peroxidase (BRASIL, 2003) no leite pasteurizado e também no cru.

As seguintes análises físico-químicas foram feitas nos três tipos de leite $(n=45)$ : acidez titulável com solução Dornic, índice crioscópico, densidade a $15^{\circ} \mathrm{C}$, teor de extrato seco total (EST) com o disco de Ackerman, teor de gordura pelo método de Gerber, teor de proteína pelo método de Semi-micro Kjeldahl (BRASIL, 2003), teores de gordura, proteína e lactose por espectrofotometria de infra-vermelho (IDF, 1996). As amostras de leite destinadas a essa análise continham o conservante bronopol a 4\%. O aparelho de infra-vermelho (Medium Infra-Red) empregado foi o Bentley 2000 ${ }^{\circledR}$ (BENTLEY INSTRUMENTS, 1995), calibrado com uma série de doze amostras de leite de vaca de composição conhecida (IDF, 1996). Antes da medição, as amostras foram aquecidas em banho-maria $\left(40^{\circ} \mathrm{C} / 15 \mathrm{~min}\right)$, homogeneizadas por inversão do recipiente e colocadas no aparelho. No leite cru foi realizada a prova do alizarol na concentração de 52\% (GUIMARÃES, 1993).

O experimento foi delineado em blocos ao acaso, sendo que o leite de cada cabra foi considerado como uma repetição. Com os resultados das análises microbiológicas foi feita estatística descritiva (média, desvio padrão e coeficiente de variação). Para avaliar o efeito do processamento sobre as características físicoquímicas do leite, as médias das variáveis quantitativas foram interpretadas por análise de variância, usando o teste de "SNK" com nível de 5\% de significância (SAMPAIO, 1998). Para avaliar o uso do aparelho de infra-vermelho e a influência do processamento nos resultados das determinações por infra-vermelho, empregou-se um esquema fatorial 3x2 (processamento x método de análise) e as médias foram interpretadas por análise de variância, usando o teste de "SNK" (SAMPAIO, 1998). Também foram calculadas as correlações (Correlação de Pearson, 5\% de significância) entre os métodos (SAMPAIO, 1998). Os cálculos foram feitos com o programa SAEG. As variáveis qualitativas (pesquisa de enzimas e prova do alizarol) não foram estatisticamente analisadas e serviram para classificar o leite.

\section{RESULTADOS E DISCUSSÃO}

Características microbiológicas do leite de cabra cru A legislação brasileira para o leite de cabra (BRASIL, 2000) não estabelece padrões microbiológicos para o leite cru, porém a contagem média de mesófilos $\left(3,85 \pm 0,18 \log \mathrm{UFC} \mathrm{mL}^{-1}\right.$, média \pm desvio padrão), método padrão para a avaliação da qualidade de produtos lácteos, foi inferior à contagem máxima (6log UFC mL ${ }^{-1}$ ) permitida para o leite bovino cru (BRASIL, 2002). Ainda não existem padrões estabelecidos pelas legislações brasileiras para a contagem de psicrotróficos, mas, com o aumento do uso de refrigeração no local de produção e durante o transporte, essa contagem tem se tornado um melhor indicador das condições de produção e armazenamento do leite. As contagens obtidas nesse experimento

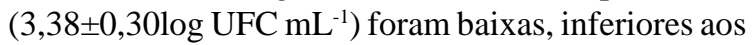
níveis considerados de risco $\left(6,70 \log \mathrm{UFC} \mathrm{mL}^{-1}\right)$ para a produção de proteases e lipases, enzimas que alteram o "flavour" do leite e cuja atividade pode ser até mais prejudicial no leite de cabra do que no de vaca (FERREIRA et al., 1992).

A pesquisa de bactérias do grupo dos coliformes é importante pela sua relação com a higiene durante a produção. Apenas três amostras de leite cru apresentaram coliformes totais no teste presuntivo, o que foi confirmado pela semeadura em ágar Levine $\left(1,01 \pm 2,34 \mathrm{NMP} \mathrm{mL}^{-1}\right)$. Entre estas, apenas uma amostra apresentou resultado positivo para coliformes fecais (0,4NMP mL $\left.{ }^{-1}\right)$. Em experimentos realizados no Brasil, EGITO et al. (1989) observaram a média de 2,04log NMP $\mathrm{mL}^{-1}$ de coliformes totais e na pesquisa de FERREIRA et al. (1992), coliformes totais e fecais estavam presentes em $1 \mathrm{~mL}$ de leite de cabra. A pesquisa de bolores e leveduras não é comumente realizada em leite, mas nesse experimento apenas cinco amostras

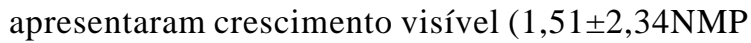
$\left.\mathrm{mL}^{-1}\right)$. O valor médio aqui observado foi inferior ao obtido (2,68log UFC mL ${ }^{-1}$ ) por ROSEIRO \& BARBOSA (1995) em leite de cabra cru.

O leite de cabra avaliado neste experimento apresentou qualidade microbiológica muito boa. Isso 
pode ser explicado pelo sistema de criação dos animais em piso ripado, evitando o contato com a cama e as fezes, o que pode diminuir a contaminação do úbere pelo uso de água tratada, pela ordenha bastante higiênica, pelo rápido resfriamento do leite e curto tempo de estocagem antes da pasteurização.

Características microbiológicas do leite de cabra processado

As contagens microbianas do leite pasteurizado foram de $1,47 \pm 0,07 \log \mathrm{UFC} \mathrm{mL} \mathrm{mL}^{-1}$ para os psicrotróficos e de 1,57log UFC $\mathrm{mL}^{-1}$ para os mesófilos, o que representou diminuição em relação ao leite cru de $99,8 \%$ e $99,6 \%$, respectivamente. Resultado semelhante ao que já foi observado por outros autores (EGITO et al., 1989; FERREIRA et al., 1992). Isso mostra que a pasteurização lenta em banho-maria, mesmo quando feita com equipamentos muito simples, pode ser eficaz para diminuir a contaminação do leite de cabra. Além disso, neste experimento, o fato de o leite ter sido pré-embalado diminuiu a possibilidade de recontaminação após pasteurização. Entretanto, não se pode deixar de ressaltar que todo processo de pasteurização elimina os microrganismos de forma percentual e quanto melhor a qualidade da matériaprima melhor será o leite pasteurizado.

A contaminação por coliformes no leite cru observada neste experimento foi muito pequena para se afirmar que o processamento utilizado foi eficiente na sua eliminação, mas EGITO et al. (1989) obtiveram redução de coliformes totais de 110 para $0,18 \mathrm{NMP}_{\mathrm{mL}} \mathrm{m}^{-1}$ e FERREIRA et al. (1992) não verificaram a presença de coliformes totais ou fecais em leite de cabra pasteurizado de forma lenta. No presente experimento, nenhuma das amostras de leite pasteurizado apresentou crescimento visível de bolores e leveduras.

Sabe-se que o congelamento pode alterar a parede celular das bactérias, prejudicando sua capacidade de multiplicação, mas também pode haver aumentos aparentes nas contagens, provocados pela separação de aglomerados de bactérias durante o armazenamento. BENEDET \& SCHWINDEN (1991) e GOMES et al. (1997) demonstraram que o congelamento por até 90 dias do leite de cabra pasteurizado não alterou significativamente suas características microbiológicas, no que diz respeito à microbiota total e aos psicrotróficos, enquanto que BENEDET \& CARVALHO (1996) observaram aumento nas contagens de mesófilos e pequeno acréscimo nas de psicrotróficos em leite cru congelado armazenado por um mês. Neste experimento, nas amostras de leite pasteurizado fresco que apresentaram crescimento bacteriano, nenhum crescimento pode ser observado após o congelamento e a estocagem.

\section{Pesquisa de enzimas}

O método colorimétrico para avaliação da fosfatase é pouco sensível e falsos negativos podem ocorrer quando a quantidade da enzima é pequena (VARNAN \& SUTHERLAND, 1994), o que é uma característica do leite de cabra (ROSEIRO \& BARBOSA, 1995). Isso explica por que em todas as amostras de leite de cabra cru e pasteurizado analisadas no experimento foram observados resultados negativos na prova de fosfatase alcalina.

A atividade da enzima lactoperoxidase pode ser determinada para saber se o leite foi super aquecido durante a pasteurização. Nesse experimento, observouse desnaturação da peroxidase em seis amostras (20\% do total), indicando a ocorrência de superaquecimento. Contudo, os resultados das análises físico-químicas ou microbiológicas dessas amostras não diferiram significativamente das outras, podendo-se concluir que esse superaquecimento não afetou a composição do leite.

Composição e propriedades físico-químicas do leite de cabra cru

O valor médio de gordura (Tabela 1) obtido no leite cru pelo método de Gerber foi superior ao mínimo (3,0\%) exigido para o leite integral (BRASIL, 2000). Já os teores de proteína obtidos pelo método de Kjeldahl foram baixos e inferiores ao valor de 3,2\% exigido pela legislação (BRASIL, 2000). Contudo, o valor médio (Tabela 1) está dentro da faixa de variação (2,45-4,18\%) obtida por BONASSI et al. (1996). Quando o leite de cabra foi analisado pelo equipamento Bentley $2000^{\circledR}$ calibrado com leite de vaca, os teores de gordura e de proteína foram semelhantes aos obtidos pelos métodos padrões e a correlação entre os métodos foi significativa $(\mathrm{P}<0,05)$ e alta $(\mathrm{r}=0,92$ para gordura e 0,71 para proteína). O coeficiente de variação calculado foi um pouco mais elevado para as determinações no equipamento automatizado em relação aos métodos tradicionais de Gerber e Kjeldahl (Tabela 1).

ZENG (1996) observou que, quando o aparelho de infra-vermelho Dairy Lab II foi calibrado com leite de cabra, o teor de gordura determinado foi 0,04\% maior em relação ao mesmo aparelho calibrado com leite bovino, mas concluiu que essa diferença ainda seria aceitável. Já em relação ao teor de proteína, os valores semelhantes obtidos no método de Kjeldahl e no equipamento Bentley $2000^{\circledR}$ calibrado com leite de vaca do presente estudo contradizem os resultados obtidos por outros pesquisadores, que mostraram 
Tabela 1 - Resultados médios, desvios-padrão (X \pm DP) e coeficientes de variação (CV) das análises físico-químicas do leite de cabra cru e após pasteurização e congelamento.

\begin{tabular}{|c|c|c|c|c|}
\hline \multirow{2}{*}{ Análise } & & Leite cru & Leite pasteurizado & Leite congelado \\
\hline & & $\mathrm{n}=15$ & $\mathrm{n}=15$ & $\mathrm{n}=15$ \\
\hline \multirow{2}{*}{ Teor de gordura - método de Gerber } & $\mathrm{X}(\%)$ & $3,7 \pm 0,59$ & $3,7 \pm 0,62$ & $3,5 \pm 0,54$ \\
\hline & CV (\%) & 15,8 & 16,9 & 15,3 \\
\hline \multirow{2}{*}{ Teor de gordura - Bentley $2000 \circledR$} & $X(\%)$ & ${ }^{\mathrm{a}} 3,8 \pm 0,67$ & a $3,7 \pm 0,68$ & $\mathrm{~b}_{3} 3 \pm 0,46$ \\
\hline & CV (\%) & 17,9 & 18,1 & 13,0 \\
\hline \multirow{2}{*}{ Teor de proteína - método Kjeldahl } & $\mathrm{X}(\%)$ & $3,0 \pm 0,20$ & $2,9 \pm 0,18$ & $3,0 \pm 0,19$ \\
\hline & CV (\%) & 6,7 & 6,2 & 6,5 \\
\hline \multirow{2}{*}{ Teor de proteína - Bentley 2000® } & X (\%) & $3,0 \pm 0,25$ & $3,0 \pm 0,25$ & $3,0 \pm 0,25$ \\
\hline & CV (\%) & 8,3 & 8,3 & 8,2 \\
\hline \multirow{2}{*}{ Teor de lactose } & X (\%) & $4,5 \pm 0,32$ & $4,5 \pm 0,33$ & $4,5 \pm 0,34$ \\
\hline & $\mathrm{CV}(\%)$ & 7,1 & 7,2 & 7,5 \\
\hline \multirow{2}{*}{ Extrato Seco Total } & X (\%) & $12,3 \pm 0,95$ & $12,4 \pm 0,95$ & $12,4 \pm 0,80$ \\
\hline & $\mathrm{CV}(\%)$ & 7,7 & 7,6 & 6,5 \\
\hline \multirow{2}{*}{ Acidez titulável } & $\mathrm{X}\left({ }^{\circ} \mathrm{D}\right)$ & $15,8 \pm 2,73$ & $16,0 \pm 2,80$ & $15,8 \pm 2,48$ \\
\hline & CV (\%) & 17,2 & 17,5 & 15,7 \\
\hline \multirow{2}{*}{ Índice crioscópico } & $\mathrm{X}\left({ }^{\circ} \mathrm{H}\right)$ & $-0,553 \pm 0,0099$ & $-0,552 \pm 0,0095$ & $-0,546 \pm 0,0062$ \\
\hline & CV (\%) & 1,79 & 1,72 & 1,13 \\
\hline \multirow{2}{*}{ Densidade } & $\mathrm{X}\left(\mathrm{g} \mathrm{mL}^{-1}\right)$ & $1,030 \pm 0,002$ & $1,031 \pm 0,001$ & $1,032 \pm 0,001$ \\
\hline & CV (\%) & 0,15 & 0,14 & 0,12 \\
\hline
\end{tabular}

${ }^{\mathrm{a}, \mathrm{b}}$ Letras diferentes na mesma linha indicam haver diferença estatisticamente significativa $(\mathrm{P}<0,05)$.

subestimação dos teores de proteína pelos aparelhos de infra-vermelho (GRAPPIN \& JEUNET, 1979; GRAPPIN, 1987; ZENG, 1996). Variações no teor de nitrogênio não-protéico ou de ácido cítrico e na relação proteína solúvel/proteína verdadeira ou caseína explicariam as diferenças entre o Kjeldahl e o infravermelho (GRAPPIN \& JEUNET, 1979; RIBADEAUDUMAS \& GRAPPIN, 1989). Assim, a composição protéica do leite de cabra analisado no experimento e sua possível semelhança com a composição do leite de vaca usado para calibrar o aparelho poderiam ser uma das explicações para os resultados obtidos.

A prova do alizarol não é considerada um bom método para avaliação da qualidade do leite de cabra (BRASIL, 2000), entretanto, o leite avaliado neste estudo mostrou-se estável a este teste. Somente duas amostras apresentaram nítida floculação e em outras duas ocorreu floculação muito ligeira. A coloração em todas elas era vermelho tijolo, indicando que o $\mathrm{pH}$ estava normal. A acidez titulável, a densidade e o índice crioscópico observados no experimento (Tabela 1) estão dentro dos padrões estabelecidos pela legislação brasileira para o leite de cabra (BRASIL, 2000).

Composição e propriedades físico-químicas do leite de cabra processado

Independente do método de análise, a pasteurização não influenciou a determinação dos teores de gordura e de proteína do leite (Tabela 1). A lactose está sujeita a alterações durante o aquecimento do leite, principalmente reações de Maillard, mas essas ocorrem em temperatura superiores a $100^{\circ} \mathrm{C}$ (WALSTRA \& JENNESS, 1984), o que explica a ausência de efeito da pasteurização sobre esse constituinte. A pasteurização pode diminuir a acidez titulável do leite ao promover a saída de $\mathrm{CO}_{2}$ e a precipitação de fosfato e ao destruir a microbiota mesofílica acidificante. No entanto, neste experimento, o valor médio do leite pasteurizado (Tabela 1) não foi estatisticamente diferente ao do leite cru. Também não foram observadas alterações no índice crioscópico ou na densidade do leite após pasteurização.

O congelamento e a estocagem do leite por uma semana não alteraram a acidez titulável do leite de cabra, o que era esperado, pois pesquisas anteriores demonstraram que a estocagem por até 60 dias não modificou a acidez do leite (GUIMARÃES, 1993; GOMES et al., 1997). Entretanto, no leite pasteurizado congelado, o teor de gordura foi menor do que o obtido no leite pasteurizado fresco, mas a diferença entre os processamentos só foi significativa $(\mathrm{P}<0,05)$ na dosagem feita pelo equipamento Bentley $2000^{\circledR}$ (Tabela 1 ). Sabese que a ocorrência de lipólise diminui os valores de teor de gordura obtidos pelo método de infra-vermelho (GRAPPIN, 1987). Contudo, como a diferença entre os resultados do teor de gordura do leite congelado obtidos 
no equipamento Bentley $2000^{\circledR}$ em relação ao método de Gerber foi significativa em apenas duas amostras (dados não apresentados), suspeita-se de um problema na homogeneização do leite antes da análise realizada pelo aparelho automatizado.

Um dos grandes problemas do congelamento do leite é a instabilidade protéica que se caracteriza por floculação envolvendo agregação física das micelas de caseína. Essa precipitação é bastante dependente da temperatura (MUIR, 1984), mas também está relacionada ao tratamento térmico ao qual o leite é submetido antes do congelamento (WALSTRA \& JENNESS, 1984). O processo de congelamento, ao diminuir o número de moléculas dissolvidas no leite, pode aumentar a crioscopia após o descongelamento (MUIR, 1984). Neste experimento, quando alguma floculação pôde ser vista, esta era mínima e quase imperceptível e não foram observadas alterações no índice crioscópico. A estabilidade protéica do leite congelado, segundo GUIMARÃES (1993), depende primariamente da estabilidade protéica do leite original, que no presente experimento foi alta, como demonstrado pelos resultados na prova do álcool alizarol.

De modo geral, não ocorreram grandes alterações nas características físico-químicas após o congelamento. Isso pode estar relacionado à qualidade da matéria-prima utilizada e ao correto processamento, isto é, congelamento rápido, além da estocagem sob temperaturas baixas. Assim, pode-se dizer que um leite de cabra apropriado ao consumo pode ser obtido em condições bastante artesanais, usando-se equipamentos simples e baratos.

\section{CONCLUSÕES}

Nas condições em que este experimento foi realizado, a pasteurização lenta em banho-maria mostrou-se eficiente na redução da carga microbiana do leite caprino e o congelamento e o armazenamento em freezer doméstico por uma semana não modificaram essas características. Além disso, esses processamentos não alteraram as propriedades físicoquímicas, as concentrações dos principais componentes ou a aparência do leite caprino.

Os resultados obtidos por meio deste estudo mostraram ainda que o aparelho de infravermelho Bentley $2000^{\circledR}$, calibrado com o leite bovino, pode ser viável para determinações dos teores de gordura e proteína do leite de cabra cru ou após o processamento. Porém, outros estudos são necessários para melhor conhecimento dos fatores que influenciam os resultados das concentrações.

\section{AGRADECIMENTO}

Ao Conselho Nacional de Desenvolvimento Científico e Tecnológico (CNPq), pela Bolsa de Produtividade de Pesquisa do autor P.V.D. Andrade

\section{REFERÊNCIAS}

APHA American Public Health Association. Standard Methods for the examination of dairy products. 16.ed. Washington, 1992. 546p.

BENEDET, H.D.; CARVALHO, M.W. Caracterização do leite de cabra no Estado de Santa Catarina, Brasil. Ciência e Tecnologia de Alimentos, v.16, n.2, p.116-119, 1996.

BENEDET, H.D.; SCHWINDEN, E. Modificações físicoquíímicas e microbiológicas do leite de cabra, congelado e armazenado. Boletim da Sociedade Brasileira de Ciência e Tecnologia de Alimentos, v.25, n.2, p.76, 1991.

BENTLEY INSTRUMENTS. Bentley 2000: operator's manual. Chaska, 1995. 77p.

BONNASSI, I.A. et al. Composição protéica do leite de cabra. Ciência e Tecnologia de Alimentos, v.16, n.3, p.218-222, 1996.

BRASIL. Regulamento técnico de identidade e qualidade do leite de cabra. Instrução Normativa nํ37 publicada no DOU de 08/11/2000, Brasília, DF.

BRASIL. Regulamentos técnicos de produção, identidade e qualidade do leite tipo $A$, do leite tipo $B$, do leite tipo $C$, do leite pasteurizado e do leite cru refrigerado. Instrução Normativa no51 publicada no DOU de 18/09/2002, Brasília, DF.

BRASIL. Métodos analíticos oficias físico-químicos para controle de leite e produtos lácteos. Instrução Normativa no22 publicada no DOU de 02/05/2003, Brasília, DF.

EGITO, A.S. et al. Avaliação da pasteurização lenta do leite de cabra no controle de coliformes totais. Sobral: EMBRAPA CNPC, 1989. N.12, 12p.

FERREIRA, C.L.L.F. et al. Qualidade microbiológica do leite de cabra armazenado a $4^{\circ} \mathrm{C}$, tratado termicamente e mantido sob refrigeração por sete dias. Revista do Instituto de Laticínios Cândido Tostes, v.47, n.279/281, p.37-40, 1992.

GOMES, M.I.F.V. et al. Características químicas, microbiológicas e sensoriais de leite de cabra congelado. Ciência e Tecnologia de Alimentos, v.17, n.2, p.111-114, 1997.

GRAPPIN, R.; JEUNET, R. Méthodes de routine pour le dosage de la matière grasse et des protéines du lait de chèvre. Lait, v.59, n.587, p.345-360, 1979.

GRAPPIN, R. Application of indirect instrumental methods to the measurement of fat and protein contents of goat and ewe milk. International Dairy Federation Bulletin, n.208, p.41-43, 1987.

GUIMARÃES, M.P.S.L. Avaliação da estabilidade físicoquímica de leite caprino congelado durante a estocagem comercial. 1993. 73f. Dissertação (Mestrado em Medicina 
Veterinária). Escola de Medicina Veterinária, Universidade Federal de Minas Gerais, Belo Horizonte.

ICMSF. International Commission on Microbiological Specifications for Foods. Microorganisms in foods. 1. Their significance and methods of enumeration. 2.ed. Toronto: University of Toronto, 1978. V.1, 431p.

IDF. International Dairy Federation. Whole milk Determination of milk fat, protein and lactose content. Guide for the operation of mid-infrared instruments. Brussels: IDF, 1996. 12p. (IDF Standards 141B).

JENNESS, R. Composition and characteristics of goat milk: review 1968-1979. Journal of Dairy Science, v.63, n.10, p.1605-1630, 1980.

MUIR, D.D. Reviews of the progress of dairy science: frozen concentrated milk. Journal of Dairy Research, v.51, n.4, p.649-664, 1984.
RIBADEAU-DUMAS, B.; GRAPPIN, R. Milk protein analysis. Lait, v.69, p.357-416, 1989.

ROSEIRO, M.L.B; BARBOSA, M. Phosphatase activity levels in pasteurized goat's milk. Journal of the Society of Dairy Technology, v.48, n.1, p.9-12, 1995.

SAMPAIO, I.B.M. Estatística aplicada à experimentação animal. Belo Horizonte: Fundação de Ensino e Pesquisa em Medicina Veterinária e Zootecnia, 1998. 221p.

VARNAM, A.H.; SUTHERLAND, J.P. Milk and milk products. London: Chapman \& Hall, 1994. 451p.

WALSTRA, P.; JENNESS, R. Dairy chemistry and physics. New York: John Wiley \& Sons, 1984. 467p.

ZENG, S.S. Comparison of goat milk standards with cow milk standards for analyses of somatic cell count, fat and protein in goat milk. Small Ruminant Research, v.21, n.3, p.221225, 1996. 